\title{
Relationship between CT air trapping criteria and lung function in small airway impairment quantification
}

Sébastien Bommart ${ }^{1,2^{*}}$, Grégory Marin ${ }^{3}$, Arnaud Bourdin ${ }^{2,4}$, Nicolas Molinari ${ }^{3}$, François Klein ${ }^{1}$, Maurice Hayot ${ }^{2,5}$, Isabelle Vachier ${ }^{4}$, Pascal Chanez ${ }^{6}$, Jacques Mercier ${ }^{2,5}$ and Hélène Vernhet-Kovacsik ${ }^{1}$

\begin{abstract}
Background: Small airways are regarded as the elective anatomic site of obstruction in most chronic airway diseases. Expiratory computed tomography (CT) is increasingly used to assess obstruction at this level but there is no consensus regarding the best quantification method. We aimed to evaluate software-assisted $C T$ quantification of air trapping for assessing small airway obstruction and determine which CT criteria better predict small airway obstruction on single breath nitrogen test (SBNT).
\end{abstract}

Methods: Eighty-nine healthy volunteers age from 60 to 90 years old, underwent spirometrically-gated inspiratory (I) and expiratory (E) CT and pulmonary function tests (PFTs) using SBNT, performed on the same day. Air trapping was estimated using dedicated software measuring on inspiratory and expiratory CT low attenuation area (LAA) lung proportion and mean lung density (MLD). CT indexes were compared to SBNT results using the Spearman correlation coefficient and hierarchical dendrogram analysis. In addition, receiver operating characteristic (ROC) curve analysis was performed to determine the optimal CT air-trapping criterion.

Results: 43 of 89 subjects $(48,3 \%)$ had dN2 value above the threshold defining small airway obstruction (i.e. $2.5 \% \mathrm{~N} 2 / \mathrm{l})$. Expiratory to inspiratory MLD ratio $(r=0.40)$ and LAA for the range $-850-1024 \mathrm{HU}(r=0.29)$ and for the range $-850-910 \mathrm{HU}(r=0.37)$ were positively correlated with SBNT results. E/I MLD was the most suitable criterion for its expression. Expiratory to inspiratory MLD ratio (E/I MLD) showed the highest AUC value (0.733) for small airway obstruction assessment.

Conclusion: Among all CT criteria, all correlating with small airway obstruction on SBNT, E/I MLD was the most suitable criterion for its expression in asymptomatic subjects with mild small airway obstruction

Trial registration: Registered at Clinicaltrials.gov, identifier: NCT01230879.

Keywords: Air trapping, Bronchiole, Single breath nitrogen test, Biomarker, Software-assisted CT quantification

\section{Background}

Chronic airway diseases are obstructive lung disorders occurring more and more frequently, therefore becoming a major public health burden worldwide [1]. Severity assessment and management of these diseases are defined according to clinical examination and routine pulmonary function tests (PFTs). However, these measurements are

\footnotetext{
* Correspondence: s-bommart@chu-montpellier.fr

'Radiology Department, CHU Montpellier, 371 avenue Doyen Gaston Giraud 34295, Montpellier cedex 05, France

${ }^{2}$ INSERM U 1046 Université Montpellier 1, Montpellier 2, Montpellier, France Full list of author information is available at the end of the article
}

not strong enough to accurately discriminate patients regarding clinical outcomes [2]. Chronic obstructive pulmonary disease (COPD) and asthma are the most common causes of such chronic airflow limitation. From a pathophysiological point of view, small airways (defined from $2 \mathrm{~mm}$ in internal diameter and downward) are regarded as the underlying elective anatomic level of airway obstruction for both disorders [3,4], but are inadequately investigated using conventional PFTs, namely "the lung's quiet zone" [5]. Specific structural changes at this level can be assessed using tools such as the singlebreath or multiple-breath nitrogen washout test (SBNT,

\section{Biomed Central}


MBNT respectively) [6]. SBNT and MBNT are time consuming and the routine uses are not widely available owing to limited access to the equipment. Due to the fact that expiratory acquisition allows indirect evaluation of bronchiolar involvement [7], computed tomography (CT) has been increasingly put forward as an appropriate noninvasive tool for refinement in the classification and treatment monitoring of COPD and asthma [8-14]. The application of an increasingly wide range of technological tools also allows post-processing by segmentation software and thus quantifies air trapping objectively. Both a decrease in mean lung density and the percentage of low attenuation area on expiratory CT have been used in various study and correlated with disease severity in COPD and asthma [15-17]. Some authors have also suggested the role of paired expiratory to inspiratory ratio or difference as a small airway marker [18-20]. However, the choice of one of these criteria may affect the results and there is, therefore, a crucial need for standardization in CT air trapping expression.

This prospective study was designed firstly to explore the validity of air trapping software-assisted CT quantification for the assessment of small airway obstruction by using SBNT as standard of reference and, secondly, to assess which was the most accurate criterion.

\section{Methods}

\section{Subjects and eligibility criteria}

Between August 2009 and April 2012, we prospectively conducted a cross-sectional study on lung aging. This specific population was chosen to select a range of subtle small airway obstruction. Eligible participants were asymptomatic, non-smokers for at least 20 years with a cumulative history $<10$ pack-years of tobacco use and without a past history of lung disease. Subjects were asked to be in good mental and physical health as assessed by medical interview and physical activity using the Voorips score questionnaire [21]. All the final study participants had normal range spirometry, specifically regarding forced expiratory volume. They were informed of the aims of the study and gave their informed consent for both pulmonary function testing and chest CT.

This study received the approval of the local research ethics committee (CPP sud Méditerranée IV) and the agreement of the French Health Products Safety Agency (ANSM) before the start of the research.

\section{Scanning techniques}

All CT examinations were performed using a 64-detector row CT scanner (LightSpeed VCT; GE Healthcare, Waukesha, USA) without the administration of contrast material. Patients were placed in the supine position. The entire chest from apex to posterior recesses was included in the cranio-caudal direction according to the following protocol: tube voltage: $120 \mathrm{kV}$, automatic tube current modulation with maximal current limited to 300 mAs, collimation: $64 \times 0.6 \mathrm{~mm}$, increment: 0.9 , reconstructed slice thickness: $1.25 \mathrm{~mm}$, tube rotation: $0.5 \mathrm{~s}$, acquisition field of view ranged from 320 to $380 \mathrm{~mm}$ depending on the patient's body habitus. Each chest CT examination was reconstructed using a standard filter.

Images were acquired using spirometric gating (WinspiroPRO; Medical International Research Waukesha, USA) to monitor lung volumes and determine respiratory endpoints. Patients were trained to breathe into a mouthpiece connected to the handheld spirometer after calibration of the spirometer according to manufacturer specifications. Breath-hold was obtained at least 3 times in inspiration and expiration using the spirometric equipment just before $\mathrm{CT}$ acquisition in supine position. Image sets were then acquired during single-breath-hold helical scanning between 90 and 100\% of previously recorded slow vital capacity in supine position. Four additional slices were acquired in the same conditions at end expiration: one through the upper lobes, one through the tracheal carina and two between the tracheal carina and the diaphragm. All DICOM images were anonymously archived and transferred to a dedicated computer for post-treatment.

\section{Quantitative assessment of air trapping by $\mathrm{CT}$}

De-identified data was processed independently and blindly by a senior radiologist with 8 years of experience interpreting chest CT images (S.B.) and also by a chest radiology fellow (F.K.). Lung parenchyma was automatically isolated from the chest wall, mediastinum and air contained within the segmental bronchi (Additional file 1: Figure S1) and then analyzed using threshold techniques and histogram computation in order to quantify lung air trapping objectively and to provide reproducible data with the use of commercially available software (Myrian, Intrasense, Montpellier, France). Measurements were done for the four levels described above combining the values found for both sides at each level. Air trapping was defined in expiratory $\mathrm{CT}$ as lung regions that failed to increase in attenuation or decrease in volume in a normal fashion compared with findings on the initial inspiratory images [22]. Given the absence of a single, validated method of CT air trapping quantification, the inspiratory and expiratory chest CT scans were scored in 3 ways, most frequently used in the literature [23].

The percentage of lung parenchyma that fell within a range of low attenuating area (LAA\%) was considered representative of air trapping: voxels between -850 and $-1024 \mathrm{HU}$, called exp -850-1024 on expiratory slices were isolated. A second threshold was also applied between -850 and $-910 \mathrm{HU}$ (exp -850-910) to avoid 
low-density values due to emphysematous or cystic lesions. Finally, mean lung density was automatically measured.

Expiratory to inspiratory ratio and the difference between these values were calculated. 4 expiratory images were matched visually by using anatomical landmarks with 4 inspiratory images with the same slice thickness from the inspiratory images. E/I, E-I and (E-I)/I were expressed using the two thresholds described above for LAA $\%$ and for MLD.

\section{Single breath nitrogen test (SBNT)}

SBNT was performed the same day, just before CT scanning. This test was used to look specifically for small airway abnormalities. This test was performed as previously reported by Bourdin and colleagues [24], using the Vmax apparatus (Vmax; Sensomedics, Yorba Linda, CA, USA) under the supervision of an expert in clinical physiology (M.H.), blinded to the CT results. Subjects were asked to breathe slowly and deeply to reach residual volume. They were then asked to inhale as deeply as possible to obtain total lung volume capacity at which point the breathing valve started the delivery of $100 \%$ O2 gas. Subjects were then asked to exhale immediately at a $0.3-0.5 \mathrm{l} / \mathrm{s}$ flow giving visual feedback on the computer screen to allow for the procedure to be followed correctly. The fractional expiratory nitrogen concentration was plotted against the expired volume. This helped determine the closing volume and the slope of this relationship when it reached the plateau known as the phase III nitrogen slope (delta N2 or dN2). See the Additional file 2: Figure S2 for the single breath nitrogen washout test curve.

\section{Statistical analysis}

Quantitative variables were expressed as means or medians and compared using the Student $t$ test or the Wilcoxon test. Qualitative variables were expressed as numbers (percentages) and compared using the Chi 2 test or the Fisher test as appropriate.

Non-parametric Spearman test was carried out to assess the relationship between functional and CT parameters. Distance and similarity between dN2 and CT air trapping criteria were then analyzed using dendrogram analysis based on the agglomerative hierarchical cluster tree. The best CT parameter was determined using receiver operating characteristic (ROC) curve analysis using standard $\mathrm{dN} 2$ cut-off $=2.5 \% \mathrm{~N} 2 / \mathrm{l}$. To test the diagnostic consistency of air trapping quantification for the two readers, inter-observer agreement was calculated using intra-class correlation coefficient [25]. A p-value of $\leq 0.05$ was considered statistically significant. The statistical analysis was performed using statistical software
SAS 9.3 (SAS Institute; Cary, NC), R 2.14.1 and SPSS 17.0 for Windows (SPSS, Chicago, Ill).

\section{Results}

Among the 101 eligible subjects, a total of 89 performed adequate spirometric maneuvers for both PFTs and CT acquisitions. Software-assisted inspiratory and expiratory lung segmentation was achievable for all these subjects. Description of the study population is provided in Table 1.

\section{Intra-class correlation coefficient values}

Raw data quantitative air trapping measures were assessed using MLD and LAA\% having attenuation below $-850 \mathrm{HU}$ or between -850 and $-910 \mathrm{HU}$. The match between the two observers yielded good to excellent inter-reader reliability for each (Additional file 3: Table S1). The lowest inter-class correlation coefficient between junior and senior radiologists was 0.91 for the fourth slice $\mathrm{EXP}_{-850-910}$.

Table 1 Demographic and spirometric characteristics of study subjects

\begin{tabular}{lcc}
\hline Variables & Mean & Std \\
\hline Age (y) & 72,03 & 8,08 \\
Height (cm) & 162,14 & 8,93 \\
Weight (kg) & 67,05 & 11,54 \\
BMI (Kg/m²) & 25,53 & 3,49 \\
FVC (I) & 3,28 & 0,89 \\
FVC (\% predicted) & 123,10 & 20,86 \\
FEV1 (I) & 2,37 & 0,64 \\
FEV1 (\% predicted) & 89,31 & 17,02 \\
FEV1/FVC & 72,69 & 6,82 \\
MEF (I) & 2,84 & 1,14 \\
MEF (\% predicted) & 110,09 & 40,98 \\
TLC (I) & 5,85 & 1,17 \\
TLC (\% predicted) & 110,95 & 15,21 \\
RV (I) & 2,58 & 0,61 \\
RV (\% predicted) & 117,13 & 26,21 \\
FRC (I) & 3,28 & 0,73 \\
FRC (\% predicted) & 111,87 & 22,64 \\
CV (I) & 2,91 & 0,80 \\
dN2 (\% slope) & 3,02 & 2,24 \\
\hline Note. Data are means &
\end{tabular}

Note. Data are means \pm standard deviations for quantitative variables. Percentages are expressed as a ratio of measured to predicted values. $F V C=$ forced vital capacity, FEV $1=$ forced expiratory volume in 1 second, $M E F=$ mid forced expiratory flow, $T L C=$ total lung capacity, $R V=$ residual volume, $F R C=$ functional residual capacity,$C V=$ closing volume, $d N 2=$ phase III nitrogen slope. 


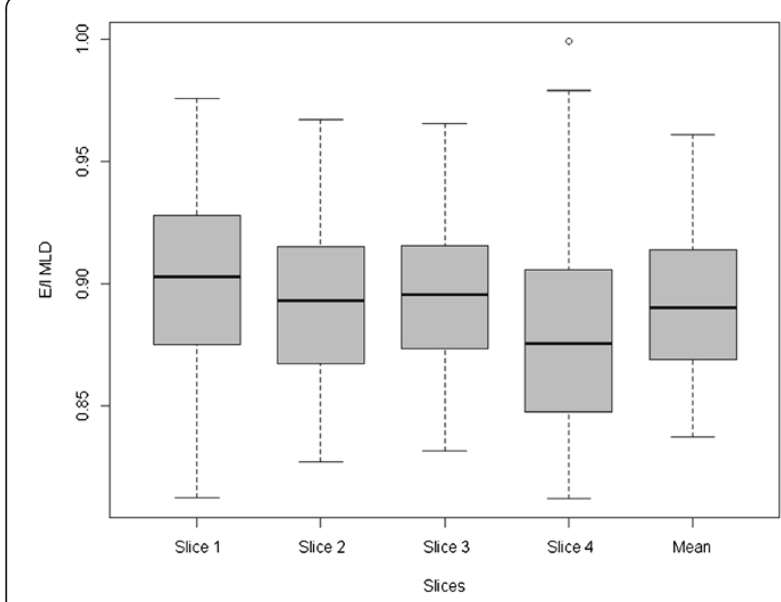

Figure 1 Box plots of air trapping represented by $E / I_{M L D}$ in 4 levels and mean of $\mathrm{E} / \mathrm{I}_{\mathrm{MLD}}$. Significant differences between slices were observed $(p=0.0002)$.

\section{Spatial Heterogeneity}

As shown in Figure 1, CT air trapping assessed by E/I MLD ratio obtained at all four levels was statistically different $(p=0.02)$ but all the four expiratory mean lung density values remained significantly correlated with $\mathrm{dN} 2$ as demonstrated by the Spearman correlation coefficient (Additional file 4: Table S2).

\section{Comparison of CT indexes for small airway obstruction assessment}

43 of 89 subjects $(48,3 \%)$ had $\mathrm{dN} 2$ value above the cutoff $(2.5 \% \mathrm{~N} 2 / \mathrm{l})$.

All CT indexes (E/I, (E-I)/I and E-I LAA\% or MLD correlated with small airway obstruction, as assessed by dN2 (Additional file 4: Table S2). Figure 2 shows the connection between $\mathrm{dN} 2$ and the CT criteria generated by hierarchical dendrogram analysis. The cluster located the furthest from $d N 2$ was $E-I_{M L D}$. The three branches the most closely related to $\mathrm{dN} 2$ in the cluster dendrogram (E/I $\mathrm{I}_{\mathrm{MLD}}$, (E-I)/ $\left.\mathrm{I}_{\mathrm{MLD}}, \mathrm{E}_{-} \mathrm{I}_{-850-910}\right)$ were then included for further ROC curve analysis to determine the criteria that yielded the highest combined sensitivity and specificity and thus the highest diagnostic value. The resulting ROC curves are shown Figures 3, 4 and 5. E/ $\mathrm{I}_{\mathrm{MLD}}$ provided the best area under the curve (AUC) value (0.714 confidence interval: $0.606,0.822)$ using $\mathrm{dN} 2$ as a reference. Similar results were obtained for (E-I)/I. When analysis was performed on the second slice individually, AUC for E/I and (E-I)/I was slightly higher (0.733; $0.630-0.836)$.

\section{Discussion}

This study reports a clear relationship between spirometrically gated $\mathrm{CT}$ air trapping quantification and physiological measurements of the small airways using SBNT. The strength of the CT quantification technique is its capacity to express small airway obstruction reliably using standard, commercially available, software. Indeed, software-assisted CT air trapping quantification was feasible in our study for all subjects who achieved adequate CT acquisitions with a high consistency between observers even for inspiratory images, matched visually by using anatomical landmarks. Expiratory to inspiratory ratio and the difference between these values were calculated to characterize CT air trapping in order to overcome error related to decrease in lung density due to alveolar enlargement likely associated with age [26-28]. $\mathrm{E} / \mathrm{I}_{\mathrm{MLD}}$ and (E-I)/I ${ }_{\mathrm{MLD}}$ exhibited the best performance characteristics to assess small airway obstruction. O. Mets and colleagues recently pointed out that $E / I_{M L D}$ was related to PFTs [29]. They showed a relationship between residual volume/Total lung volume capacity (RV/ TLC) and E/I MLD in a population of current and former heavy smokers in a lung cancer screening cohort. Nonetheless, RV/TLC reflects static lung hyperinflation and

Cluster Dendrogram

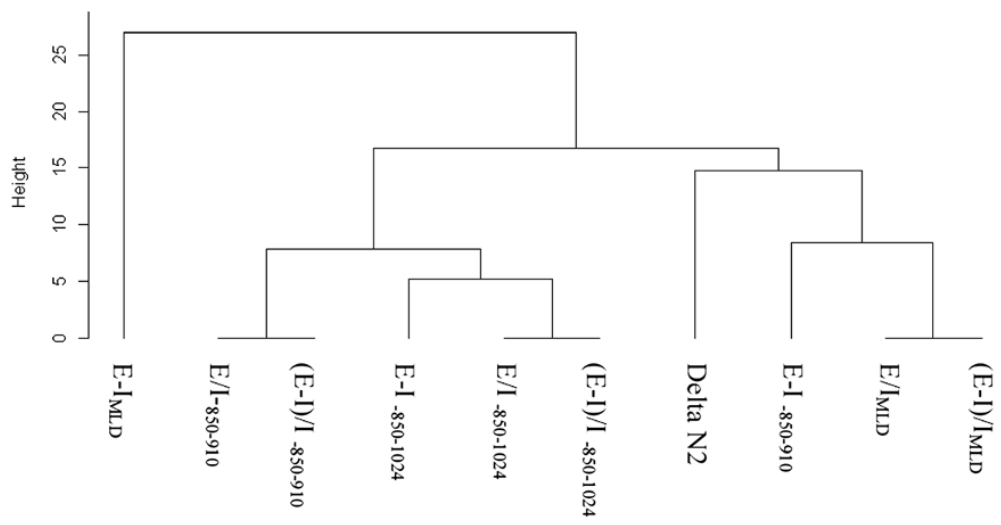

Figure 2 Hierarchical dendrogram analysis to evaluate distance and similarity between dN2 and CT air trapping criteria. 


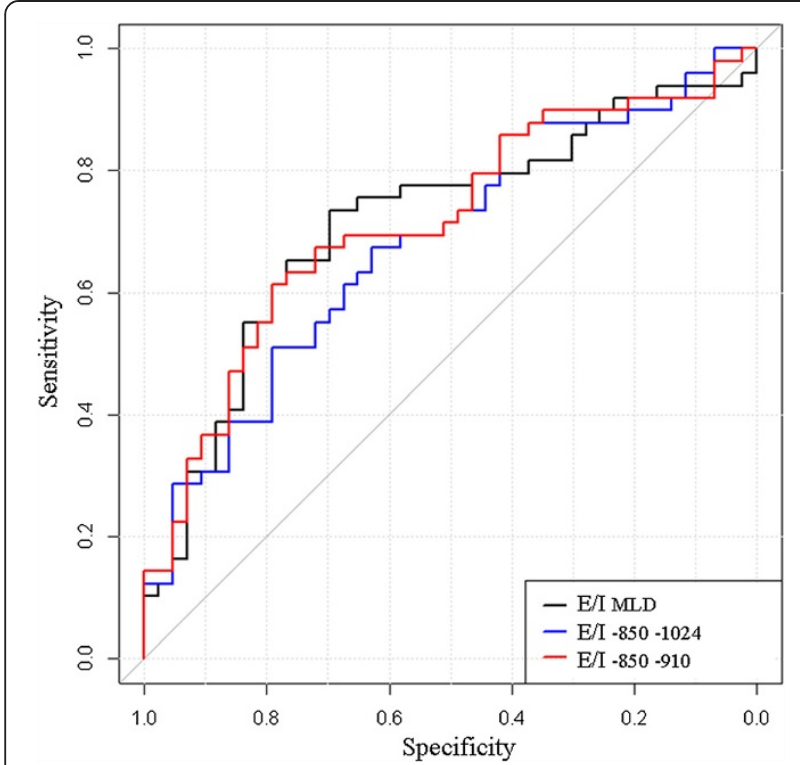

Figure 3 Receiver-operating characteristic (ROC) curves show the diagnostic performance of E/I using $\mathrm{dN2}$ as a functional test of airway obstruction (dN2 cut-off $=\mathbf{2 . 5} \% \mathrm{~N} 2 / \mathrm{l}$ ). The best threshold is reported, alongside the sensitivity and specificity: $E / I_{M L D}=0.89(0.70 ; 0.73)-E / I_{-850-1024}=0.32(0.63 ; 0.67)-$ $E / I_{-850-910}=0.29(0.79 ; 0.61)$.

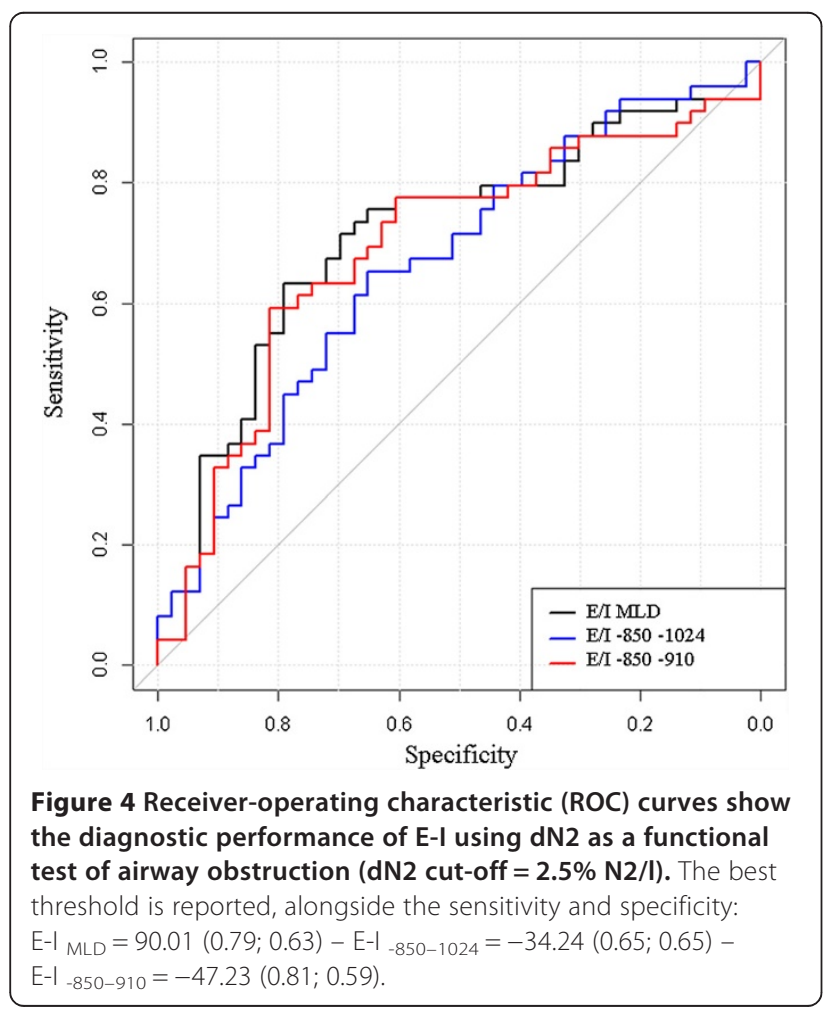

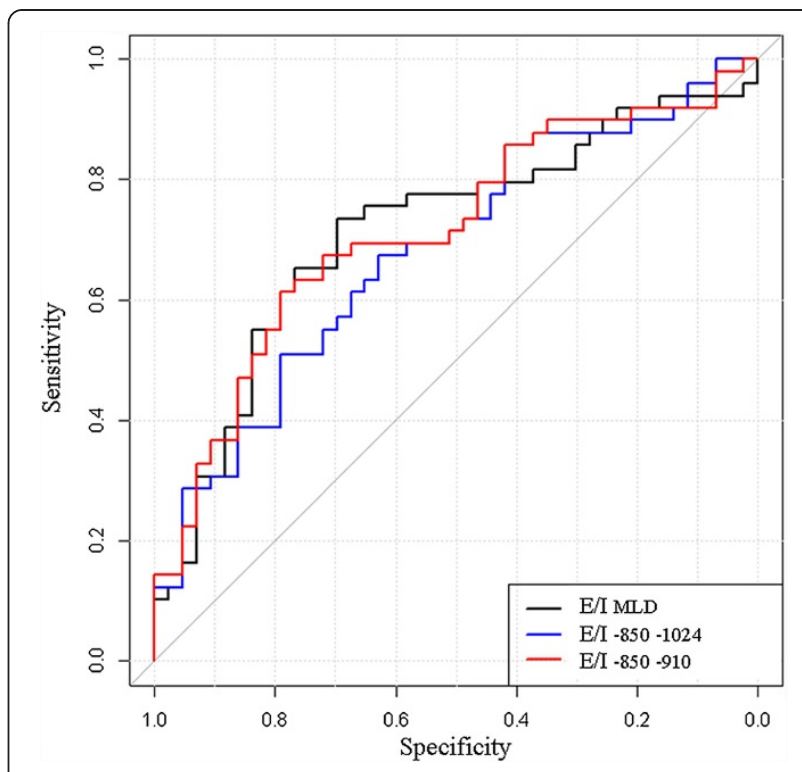

Figure 5 Receiver-operating characteristic (ROC) curves show the diagnostic performance of $(\mathrm{E}-\mathrm{I}) / \mathrm{I}$ using $\mathrm{dN2}$ as a functional test of airway obstruction (dN2 cut-off $=\mathbf{2 . 5} \% \mathrm{~N} 2 / \mathrm{l}$ ). The best threshold is reported, alongside the sensitivity and specificity: $(E-I) / I_{M L D}=-0.11(0.70 ; 0.73)-(E-I) / I-850-1024=-0.68(0.63 ; 0.67)-$ $(\mathrm{E}-\mathrm{I}) / \mathrm{I}_{-850-910}=-0.70(0.79 ; 0.61)$.

the value may be influenced either by the presence of small airway obstruction or by emphysema. Furthermore, discrimination is possible only in severe cases of hyperinflation. Only 38 of the 427 heavy smokers subjects presented abnormal RV/TLC in the Mets study. There is currently no functional test allowing perfect non-invasive assessment of small airways. Nonetheless inert gas washout tests such as SBNT provide information on ventilation inhomogeneity that allows sensitive detection of small airway obstruction even when RV/TLC or other standard spirometry values are normal [30-33]. Our sample population aged 60 and older and the selection criteria used offered a well-defined population of subjects with a range of small airway obstruction that may be attributed to normal ageing [34,35]. Furthermore, people included in this study achieved reproducible maneuvers that are a key point for SBNT validity [6].

The correlation found in our study between CT and SBNT showed that CT air trapping can detect even mild to moderate small airway obstruction as seen in our subjects who were all asymptomatic but nevertheless having physiological modifications. The aim was to validate CT air trapping quantification from a homogeneous model that could be further applied to various chronic obstruction situations such as COPD or asthma.

Our study has several potential limitations. First, we did not used whole expiratory volume also described for air trapping assessment but only a single set of four 
expiratory slices $[19,36]$. We did this because of the difficulty for subjects to sustain breath-hold at low lung volumes and furthermore in keeping with the recommendation made by the ethics committee to limit the radiation dose as well as the "As Low As Reasonably Achievable" principle. We cannot know from this study whether analysis on the whole lung volume would have improved the correlations, nonetheless our results showed similar significant air trapping heterogeneity between the upper, middle, and lower regions to that found by Bankier and colleagues in their work on a lung transplant population [37]. Regardless of slice level, each remained significantly associated with dN2. Even if AUC was slightly higher for $\mathrm{E} / \mathrm{I}_{\mathrm{MLD}}$ in slice 2 (i.e. through the carina), we did not recommend the use of only one expiratory slice as its index could not be applied to pathologies such as asthma, which have been proven to have widely heterogeneous spread [38].

Second, although use of a spirometer to control lung volume during acquisition is not standard practice, in this study it provided proof of inspiration and expiration volume.

Another potential limitation is the lack of emphysematous lesions in our population. The elective site of measurement should be adapted in COPD patients with such lesions as stated by Matsuoka [39].

\section{Conclusions}

Our study demonstrated that in asymptomatic subjects with small airway obstruction, software-assisted CT air trapping quantification correlated with SBNT. E/I and (E-I)/I MLD are equally representative of small airway obstruction and could be used as a small airway obstruction biomarker.

\section{Additional files}

Additional file 1: Figure S1. Automated quantification of air trapping using segmentation software obtained in a 64-year old woman. Axial expiratory images. Color code: Blue for total lung parenchyma (areas with attenuation of -500 to $-1024 \mathrm{HU}$ ). Red for attenuation between -850 and $-910 \mathrm{HU}$ and green for attenuation less than $-910 \mathrm{HU}$.

Additional file 2: Figure S2. Schematic representation of single breath nitrogen test.

Additional file 3: Table S1. Comparison of the inter-observer agreement (Intra-Class correlation*).

Additional file 4: Table S2. Spearman correlations between Delta N2 and (expiratory/inspiratory) values, for the four slices.

\section{Abbreviations}

COPD: Chronic obstructive pulmonary disease; CT: Computed tomography; delta N2: Phase III nitrogen slope; LAA: Low attenuation area; MBNT: Multi breath nitrogen test; MLD: Mean lung density; PFT: Pulmonary function test; ROC: Receiver operating characteristic; RV: Residual volume; SBNT: Single breath nitrogen test; TLC: Total lung volume capacity.

\section{Competing interests}

The study was funded by a grant from the French Ministry of Health (Programme Hospitalier de Recherche Clinique 2008). No potential conflicts of interest relevant to this article were reported for any authors.

\section{Authors' contribution}

SB and HK were responsible for the concept and design of the study. SB drafted and wrote the paper. AB participates in the study design and helped to draft the manuscript. GM and NM helped to perform statistical analysis. All authors contributed to the clinical data collection, data analysis and review the manuscript. All authors read and approved the final manuscript.

\section{Acknowledgements}

We thank all volunteers who participated in this research study and Melina Bouet for her excellent research assistance.

\section{Author details}

${ }^{1}$ Radiology Department, CHU Montpellier, 371 avenue Doyen Gaston Giraud 34295, Montpellier cedex 05, France. ${ }^{2}$ INSERM U 1046 Université Montpellier 1, Montpellier 2, Montpellier, France. ${ }^{3}$ Statistics Department CHU Montpellier, Montpellier, France. ${ }^{4}$ Respiratory Disease Department, CHU Montpellier, Montpellier, France. ${ }^{5}$ Clinical Physiology Department, CHU Montpellier, Montpellier, France. ${ }^{6}$ Respiratory Disease Department, CHU Marseille, Marseille, France.

Received: 29 August 2013 Accepted: 14 February 2014

Published: 28 February 2014

\section{References}

1. Mannino DM, Buist AS: Global burden of COPD: risk factors, prevalence, and future trends. Lancet 2007, 370:765-773.

2. Vestbo J, Hurd SS, Agusti AG, Jones PW, Vogelmeier C, Anzueto A, Barnes PJ, Fabbri LM, Martinez FJ, Nishimura M, Stockley RA, Sin DD, RodriguezRoisin R: Global strategy for the diagnosis, management and prevention of chronic obstructive pulmonary disease, GOLD executive summary. Am J Respir Crit Care Med 2013, 187(4):347-365.

3. McDonough JE, Yuan R, Suzuki M, Seyednejad N, Elliot WM, Sanchez PG, Wright AC, Gefter WB, Litzky L, Coxson HO, Paré PD, Sin DD, Pierce RA, Woods JC, MCWilliams AM, Mayo JR, Lam SC, Cooper JD, Hogg JC: Small-airway obstruction and emphysema in chronic obstructive pulmonary disease. N Engl J Med 2011, 365(17):1567-1575.

4. Timmins SC, Diba C, Farrow CE, Schoeffel RE, Berend N, Salome CM, King GG: The relationship between airflow obstruction, emphysema extent and small airways function in COPD. Chest 2012, 142(2):312-319.

5. Mead J: The lung's "quiet zone". N Engl J Med 1970, 282:1318-1319.

6. Robinson PD, Latzin P, Verbanck S, Hall GL, Horsley A, Grappa M, Thamrin C, Arets HG, Aurora P, Fuchs SI, King GG, Lum S, Macleod K, Paiva M, Pillow JJ, Ranganathan S, Ratjen F, Singer F, Sonnappa S, Stocks J, Subbarao P,

Thompson BR, Gustafsson PM: Consensus statement for inert gas washout measurement using multiple- and single- breath tests. Eur Respir J 2013, 41(3):507-522.

7. Laurent F, Latrabe V, Raherison C, Marthan R, Tunon-de-Lara JM: Functional significance of air trapping detected in moderate asthma. Eur Radiol 2000, 10(9):1404-1410.

8. Montaudon $M$, Lederlin M, Reich S, Begueret $H$, Tunon-de-Lara JM, Marthan $\mathrm{R}$, Berger $\mathrm{P}$, Laurent F: Bronchial measurements in patients with asthma: comparison of quantitative thin-section $\mathrm{CT}$ findings with those in healthy subjects and correlation with pathologic findings. Radiology 2009, 253(3):844-853.

9. Matsuoka S, Yamashiro T, Washko GR, Kurihara Y, Nakajima Y, Hatabu H: Quantitative CT assessment of chronic obstructive pulmonary disease. Radiographics 2010, 30(1):55-66.

10. Gupta S, Siddiqui S, Haldar P, Entwisle JJ, Mawby D, Wardlaw AJ, Bradding P, Pavord ID, Green RH, Brightling CE: Quantitative analysis of high-resolution computed tomography scans in severe asthma subphenotypes. Thorax 2010, 65(9):775-781.

11. Mets OM, Schmidt M, Buckens CF, Gondrie MJ, Isgum I, Oudkerk M, Vliegenthart $\mathrm{R}$, de Koning HJ, van der Aalst CM, Prokop M, Lammers JW, Zanen P, Mohamed Hoesein FA, Mali WP, van Ginneken B, van Rikxoort EM, de Jong PA: Diagnosis of chronic obstructive pulmonary disease in lung cancer screening Computed Tomography scans: independent 
contribution of emphysema, air trapping and bronchial wall thickening Respir Res 2013, 186:157-165.

12. Bafadhel M, Umar I, Gupta S, Raj JV, Vara DD, Entwisle JJ, Pavord ID, Brightling $C E$, Siddiqui $S$ : The role of $C T$ scanning in multidimensional phenotyping of COPD. Chest 2011, 140(3):634-642.

13. Hackx M, Bankier AA, Gevenois PA: Chronic obstructive pulmonary disease: CT quantification of airways disease. Radiology 2012, 265(1):34-48.

14. Brillet PY, Grenier PA, Fetita Cl, Beigelman-Aubry C, Ould-Hmeidi Y, Ortner M, Nachbaur G, Adamek L, Chanez P: Relationship between the airway wall area and asthma control score in moderate persistent asthma. Eur Radiol 2013, 23(6):1594-1602.

15. Coxson HO, Mayo J, Lam S, Santyr G, Parraga G, Sin DD: New and current clinical imaging techniques to study chronic obstructive pulmonary disease. Am J Respir Crit Care Med 2009, 180(7):588-597.

16. Devakonda A, Raoof S, Sung A, Travis WD, Naidich D: Bronchiolar disorders: a clinical-radiological diagnostic algorithm. Chest 2010, 137(4):938-951.

17. de Jong PA, Vos R, Verleden GM, Vanaudenaerde BM, Verschakelen JA: Thin-section computed tomography findings before and after azithromycin treatment of neutrophilic reversible lung allograft dysfunction. Eur Radiol 2011, 21(12):2466-2474.

18. Matsuoka S, Kurihara Y, Yagihashi K, Hoshino M, Watanabe N, Nakajima Y: Quantitative assessment of air trapping in chronic obstructive pulmonary disease using inspiratory and expiratory volumetric MDCT. AJR Am J Roentgenol 2008, 190(3):762-769.

19. Hersh CP, Washko GR, Estépar RSJ, Lutz S, Friedman PJ, Han MK, Hokanson JE, Judy PF, Lynch DA, Make BJ, Marchetti N, Newell JD Jr, Sciurba FC, Crapo $J D$, Silverman EK, COPDGene Investigators: Paired inspiratory-expiratory chest $C T$ scans to assess for small airways disease in COPD. Respir Res 2013, 170:301-307.

20. Chae EJ, Kim TB, Cho YS, Park CS, Seo JB, Kim N, Moon HB: Airway measurement for airway remodeling defined by post-Bronchodilator FEV1/FVC in asthma: investigation using inspiration-expiration computed tomography. Allergy Asthma Immunol Res 2011, 3(2):111-117.

21. Voorrips $L E$, Ravelli $A C$, Dongelmans $P C$, Deurenberg $P$, Van Staveren WA A physical activity questionnaire for the elderly. Med Sci Sports Exerc 1991, 23(8):974-979.

22. Arakawa H, Webb WR, McCowin M, Katsou G, Lee KN, Seitz RF: Inhomogeneous lung attenuation at thin-section CT: diagnostic value of expiratory scans. Radiology 1998, 206(1):89-94.

23. Mets OM, Murphy K, Zanen P, Gietma HA, Lammers JW, van Ginneken B, Prokop M, de Jong PA: The relationship between lung function impairment and quantitative computed tomography in chronic obstructive pulmonary disease. Eur Radiol 2012, 22(1):120-128.

24. Bourdin A, Paganin F, Prefaut C, Kieseler D, Godard P, Chanez P: Nitrogen washout slope in poorly controlled asthma. Allergy 2006, 61(1):85-89.

25. Shrout PE, Fleiss JL: Intraclass correlations: uses in assessing rater reliability. Psychol Bull 1979, 86(2):420-428.

26. Waters B, Owers-Bradley J, Silverman M: Acinar structure in symptom-free adults by Helium-3 magnetic resonance. Am J Respir Crit Care Med 2006, 173(8):847-851.

27. Verbanck S, Thompson BR, Schuermans D, Kalsi H, Biddiscombe M, Stuart-andrews C, Hanon S, Van Muylem A, Paiva M, Vincken W, Usmani O: Ventilation heterogeneity in the acinar and conductive zones of the normal ageing lung. Thorax 2012, 67(9):789-795.

28. Gillooly M, Lamb D: Airspace size in lungs of lifelong non-smokers: effect of age and sex. Thorax 1993, 48(1):39-43.

29. Mets OM, Zanen P, Lammers JW, Isgum I, Gietema HA, van Ginneken B, Prokop M, de Jong PA: Early identification of small airways disease on lung cancer screening CT: comparison of current air trapping measures. Lung 2012, 190(6):629-633.

30. Gennimata SA, Palamidas A, Karakontaki F, Kosmans EN, Koutsoukou A Loukides S, Koulouris NG: Pathophysiology of evolution of small airways disease to overt COPD. COPD 2010, 7(4):269-275.

31. Bourdin A, Kotsimbos T, Nguyen K, Vachier I, Mainprice B, Farce M, Paganin F, Marty-Ané C, Vernhet $\mathrm{H}$, Godard P, Chanez P: Non-invasive assessment of small airway remodelling in smokers. COPD 2010, 7(2):102-110.

32. Cosio M, Ghezzo H, Hogg JC, Corbin R, Loveland M, Dosman J, Macklem PT: The relations between structural changes in small airways and pulmonary-function tests. N Engl J Med 1978, 298(23):1277-1281.
33. Burgel PR: The role of small airways in obstructive airway diseases. Eur Respir Rev 2011, 20(119):23-33.

34. Hansell DM: Thin-section CT, of the lungs: the Hinterland of normal. Radiology 2010, 256(3):695-711.

35. Meyer KC: Impact of aging on the lung. Semin Respir Crit Care Med 2010, 31(5):519-520

36. Galbán CJ, Han MK, Boes JL, Chughtai KA, Meyer CR, Johnson TD, Galbán S, Rehemtulla A, Kazerooni EA, Martinez FJ, Ross BD: Computed tomography-based biomarker provides unique signature of COPD phenotypes and disease progression. Nat Med 2012, 18(11):1711-1715.

37. Bankier AA, Mehrain S, Kienzl D, Weber M, Estenne M, Gevenois PA: Regional heterogeneity of air trapping at expiratory thin-section $\mathrm{CT}$ of patients with bronchiolitis: potential implications for dose reduction and CT protocol planning. Radiology 2008, 247(3):862-870.

38. Aysola R, de Lange EE, Castro M, Altes TA: Demonstration of the heterogeneous distribution of asthma in the lungs using $\mathrm{CT}$ and hyperpolarized helium-3 MRI. J Magn Reson Imaging 2010, 32(6):1379-1387.

39. Matsuoka S, Kurihara Y, Yagihashi K, Nakajima Y: Quantitative assessement of peripheral airway obstruction on paired expiratory/inspiratory thin-section computed tomography in chronic obtructive pulmonary disease with emphysema. J Comput Assist Tomogr 2007, 31(3):384-389.

doi:10.1186/1471-2466-14-29

Cite this article as: Bommart et al: Relationship between CT air trapping criteria and lung function in small airway impairment quantification. BMC Pulmonary Medicine 2014 14:29.

\section{Submit your next manuscript to BioMed Central and take full advantage of:}

- Convenient online submission

- Thorough peer review

- No space constraints or color figure charges

- Immediate publication on acceptance

- Inclusion in PubMed, CAS, Scopus and Google Scholar

- Research which is freely available for redistribution 